\section{Effective COVID-19 prevention and control in areas of ultra-dense population: Lessons from Macau} SAR

\author{
Xueni Bian ${ }^{1}$, Lan $\mathrm{Yao}^{2,3}$ and Ying Bian ${ }^{4 *}$ \\ ${ }^{1}$ Department of Life Sciences, Imperial College London, SW7 2BU, UK \\ ${ }^{2}$ School of Medicine and Health Management, Huazhong University of Science and Technology, \\ Wuhan, Hubei Province, China \\ ${ }^{3}$ Senior Consultant of Health Administration, Macau Health Bureau, Macau SAR, China \\ ${ }^{4}$ State Key Laboratory of Quality Research in Chinese Medicine, Institute of Chinese Medical \\ Sciences, University of Macau, Macau SAR, China
}

\section{Abstract}

In this paper we summarise, in chronological order, all COVID-19 preventive measures undertaken by the Macau Special Administrative Region (SAR) government during the first quarter of 2020. The information and narrative contained herein may be of useful to other parts of the world in COVID-19 control and prevention, especially cities with ultra-high population densities. The four main lessons from Macau SAR are: (1) Proactive leadership and early prevention. (2) Strict adherence to community endemic control. (3) Clear prioritising of public health. (4) Planed relief for financial hardships amidst the post-pandemic recession.

\section{More Information}

*Address for Correspondence: Ying Bian, State Key Laboratory of Quality Research in Chinese Medicine, Institute of Chinese Medical Sciences, University of Macau, Macau SAR, China, Email: bianying@um.edu.mo

Submitted: 22 May 2020

Approved: 03 June 2020

Published: 04 June 2020

How to cite this article: Bian X, Yao L, Bian Y. Effective COVID-19 prevention and control in areas of ultra-dense population: Lessons from Macau SAR. J Clin Intensive Care Med. 2020; 5: 022-025.

DOI: 10.29328/journal.jcicm.1001031

Copyright: ( 2020 Bian X, et al. This is an open access article distributed under the Creative Commons Attribution License, which permits unrestricted use, distribution, and reproduction in any medium, provided the original work is properly cited.

Abbreviations: COVID: Coronavirus Disease; SAR: Special Administrative Region; SME: Small-Medium Enterprise

\section{(W) Check for updates \\ OPEN ACCESS}

\section{Introduction}

Macau (Special Administrative Region; People's Republic of China) is a coastal resort city situated at the southernmost tip of China, adjoining the Mainland to its north, and adjacent to the busy entrepôt of Hong Kong some $64 \mathrm{~km}$ to its East. The territory of Macau - a modest size of 33 kilometre-square - is inhabited by circa 672,000 inhabitants: a population density amounting to 20,426 per kilometre-square. By these official quarterly estimates from $2019^{1}$, Macau ranks as the most densely populated region in the world: its $17^{\text {th }}$ consecutive years in that position. In addition to dense population, Macau is a world gambling capital frequently anointed as being the "Vegas of Asia". Not only is the economy heavily reliant on the local gaming industry, the region receives as much as 39.4 million visitors annually, of which $82.5 \%$ [1] originate from Mainland China (source dated 2019).

One can infer the colossal weight foisted upon the Macau society by the COVID-19 outbreak. Not to mention the compounding difficulties due to the outbreak coinciding with the Spring Festival, East Asia's most widely celebrated traditional holiday. A firm regime for COVID-19 prevention and control is not a luxury but an absolute necessity. While the global number of COVID-19 cases reaches 1,100,53 with 67,480 deaths worldwide [2], perhaps a standing testimony of Macau's competency at navigating this pivotal task is that, since its first positive-testing patient (tourist originating from Wuhan, China, $22^{\text {nd }}$ January), the number of confirmed cases within Macau tallies up to 45 to date. This metric, in comparison, is dwarfed by that from the neighbouring metropolis of Hong Kong, with confirmed cases tallying to 914 [3] (date of writing: $14^{\text {th }}$ April 2020).

The purpose of this article is to, firstly, review the four main phases of COVID-19 prevention and control, as implemented in Macau; secondly, it summarises Macau's response for an immensely successful COVID-19 control.

\section{Four phases of prevention and control in Macau (Figure 1)}

Early stage: the initial sirens: On $31^{\text {st }}$ December 2019, the Macau Government heeded first warnings from the China National Health Commission: notice of there being a singular case of pneumonia with unknown etiology having been reported from Wuhan. Warnings ensued with regards to strengthening contact with the Mainland, Hong Kong, and 


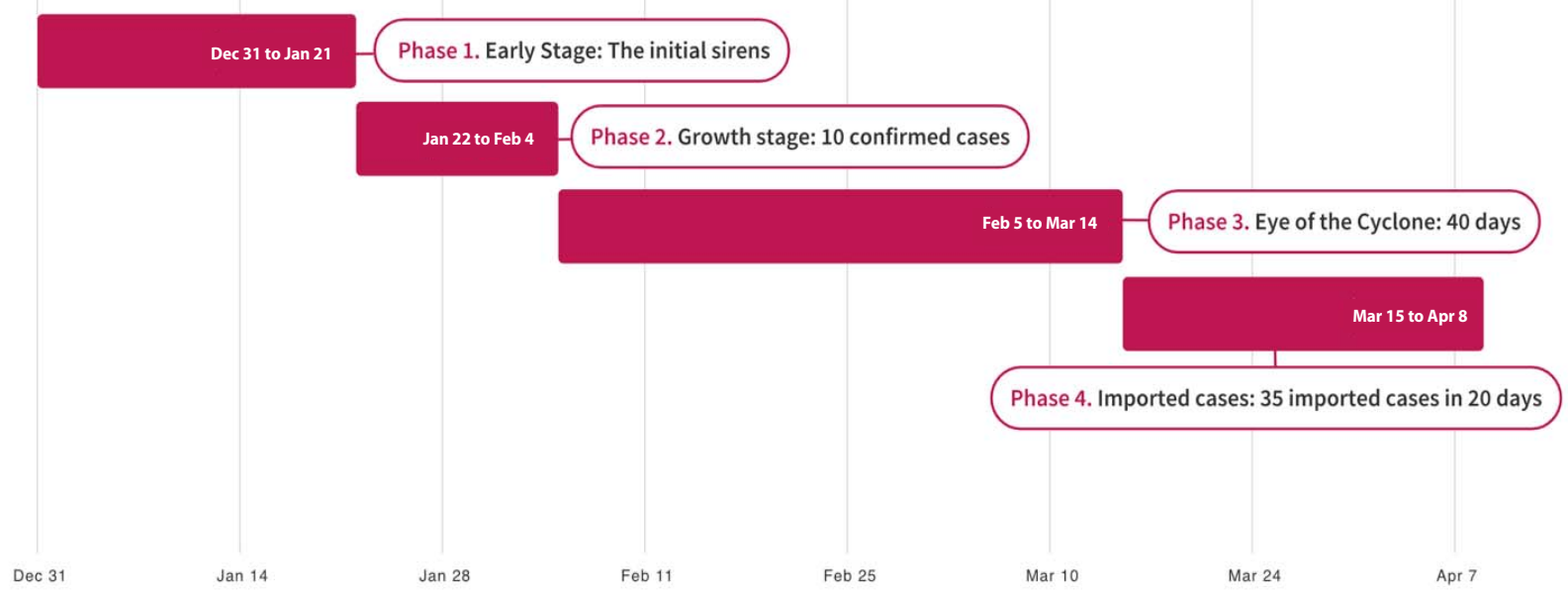

Figure 1: Four phases of prevention and control in Macau.

WHO, as well as exercising precautionary measures aboard flights to and from Wuhan. By $5^{\text {th }}$ January 2020, the Macao government convened initial meetings with regards to "cases of pneumonia with unknown etiology", which resolved to raise local warning signals to Level III (Moderate Severity) and called on general vigilance among Macau residents working and studying in Wuhan. $9^{\text {th }}$ January brought first news of fatality within Wuhan [4]. Between 13-14 ${ }^{\text {th }}$ January, the Macau Health Bureau dispatched teams of experts to Wuhan to gauge the situation of the outbreak, and to contribute to its treatment, prevention, and control measures. $21^{\text {st }}$ January saw the establishment of Macau's "Novel Coronavirus Response and Coordination Centre", chaired by the special administrative region's Chief Executive, Mr. Ho Iat Seng [5].

Growth stage: 10 confirmed cases: Between 22-23 $3^{\text {rd }}$ January, Macau detected two imported cases. Both patients were tourists originating from Wuhan. Immediately after the diagnoses, Macau launched its Public Health Clinical Centre, providing a venue for clinical observation, complete with 120 beds. The government initiated a suite of prevention and control measures, including but not limited to: border control, temperature-checks, suspension of organised tourism to and from Wuhan, cancellation of New Year festivities, postponement of school openings, closure of entertainment venues, curtailment of visit-time at hospitals, and suspension of all unurgent surgery. At the same time, the Health Bureau launched a supply plan for masks, ensuring a functional supply-chain for residents. Between $26^{\text {th }}$ January to $1^{\text {st }}$ February, five additional imported cases from Wuhan were detected. The very first case of community transmission was detected on the $2^{\text {nd }}$ February, quickly followed by an additional local testing positive on the $4^{\text {th }}$. This brings the tally of confirmed cases up to 10 , seven of which were imported from Wuhan, and three local [6]. It is at this critical point in the outbreak, $15^{\text {th }}$ February, when the government made the unprecedented decision to temporarily shut all 41 casinos, theatres, bars, clubs, and other venues of entertainment for 15 days. The consequential economic toll of this momentous decision is immense: Macau's gaming industry rolls in a gross revenue of 37.5 billion USD per annum (1.56 billion USD per half-month) [7], with huge collateral losses to Macau's GDP.

Eye of the Cyclone: The aforementioned prevention and control measures have achieved remarkable, near-ideal results: $5^{\text {th }}$ February and $15^{\text {th }}$ March marks a period of 40 consecutive days with no new cases being reported within Macau. It is very well worth mentioning that during this period, with the latest of Macau's diagnosed patients discharged from hospital care on the $6^{\text {th }}$ of March, all 10 COVID-19 patients diagnosed in Macau have recovered, with no new cases being reported [8]. The Macau health service system has achieved what was appraised by local media as "zero intensive-cases, zero deaths, zero nosocomial infections." On $9^{\text {th }}$ February, the Macao Polling Research Association released an online survey gauging public opinion "on the effectiveness of local COVID-19 outbreak prevention measures", which returned $90 \%$ positive responses.

On the $7^{\text {th }}$ of March, in a concerted effort between the Central Government, the Macao Liaison Office, and relevant departments of Hubei Province, 57 Macau residents who were previously located throughout Hubei were assembled at Wuhan Airport [9]. All residents were retrieved to Macau S.A.R. safely, as well as the aircraft's accompanying medical staff, administrative staff, and crew members.

Imported cases: shifting focus for current work: By mid-March, COVID-19 outbreaks have mushroomed in several countries at an international scale. Imported cases within Macau saw a sharp increase starting from the $15^{\text {th }}$ of March, with a 26-year-old Korean employee testing positive [10]. To date, the cumulative number of newly imported cases tallied to 35 in just 20 days, bringing summed number of cases within Macau to 45. 
Due to the surge in imported cases, the Macau government imposed further border restrictions on the $18^{\text {th }}$ March: all border entrants with travel-histories to the Mainland, Hong Kong, or Taiwan within 14 days prior to entry to Macau must undergo an obligatory 14-day quarantine. Designated hotels and the Public Health Clinical Centre were dedicated to quarantining persons from high-risk areas, with everyone else required to follow home-isolation polices. A formalised health declaration, in which any concealment or falsity is punishable by law, were also enforced prior to granting entry [11].

\section{Lessons from Macau}

Throughout the period when the epicentre of the outbreak remained in East Asia, only 10 confirmed cases were reported within Macau. Even in the face of high risk for importing cases, following a shift of the epicentre to European and North American outbreaks, we have yet to observe largescale community infections within Macau, except for the 35 imported cases already at hand. This is ample evidence that the outbreak prevention measures implemented in Macau are worthy of our attention and promotion.

The government being proactive: As a world-renowned gambling destination, the number of tourists entering Macau annually (39.4 million for the year 2019) outnumbers local residents by nearly 60 times. Therefore, implementing the following measures at its borders (active from $27^{\text {th }}$ January) have played pivotal roles to controlling pathogen entry:

I. Prior to granting entry, all non-residents from (or have recently been to) Hubei Province are required to produce evidence of negative-test results for COVID-19, issued by a certifiable medical institution.

II. After granting entry (to Macau), all persons who have visited Hubei within 14 days prior to entering Macau are denied entry to gambling venues (the main destination for tourists).

III. At the time of implementing these measures, the government contacted all 1113 tourists from Hubei who have not yet departed Macau. Post-screening for symptoms, they were advised to leave. If they had chosen to continue their stay, Black Sand Youth Hostel and the Municipal Hac-Sa Training Centre were dedicated for their mandatory isolation.

\section{Borders' opening hours were shortened altogether}

V. Large-scale enterprises (based primarily in Macau) sought accommodation within Macau for employees who would normally commute across borders, with the purpose of reducing flux in the community.

Other than preventing pathogen entry, the government also took initiative to control community infection:

I. Residents holidaying in the Mainland were called to return as soon as possible and self-isolate for 14 days.

II. Postponement of opening schools .

\section{Mandatory masks to be worn by casino staff.}

IV. Public consultation hotline dedicated to engagement and communication (of epidemiology, virology, COVID-19 symptoms, medical service available, etc) alleviated public anxiety and misinformation.

The S.A.R.'s Chief Executive demonstrating sound public health awareness, prioritising COVID-19 over economic factors: The 15-day suspension starting $5^{\text {th }}$ February temporarily shut down 41 Casinos, six gaming companies, Macau Lottery Co. Ltd., the Jockey Club, as well as a myriad of entertainment revenues. The share price of Casino fell in response. Reports issued by Jefferies Investment Banking stated that the expected revenue for February had been 75 million USD per day, and that if the half-month suspension is to follow through, net revenue for the month of February shall only amount to 1.125 billion USD: a yearon-year decline of $64.5 \%$ (bearing in mind that the daily running cost of a casino is circa $2.73-7.52$ million USD). In deciding to go forth with a suspension of the gaming industry, the government of the largest gambling mecca of our world demonstrates soundness of mind and coherence in priority: that which places human lives and public health as paramount interest over the economy. Chief Executive He Yicheng told the media: "The government has seen fiscal surplus for many years. It is time to spend that money. Money can be re-earned, but the health of the people is irrecoverable."

Healthcare being made affordable: of the 10 cases diagnosed in the early phase, seven were tourists from Wuhan. Without medical insurance based in Macau, the expenses were necessarily borne by patients themselves. However, the government mandated that the public hospital (Centro Hospitalar Conde de São Januário) should prioritise treatment. It is only after the patient's discharge, and not before, when the expenses should be considered. Patients who are unable to pay may be considered for waivers or discounts. The Macau government health service system coordinates alongside Mainland China so that fees can be negotiated, and for payments being made only after the patient return to their hometowns safely. In comparison to charges and finances, the timely treatment and recovery from COVID-19 per-se were of paramount urgency.

The orderly resuming production by mid-march: By mid-March, Macau's public sector has resumed basic external services, with various industries having actively resumed production in an orderly manner. As the aftermath of a series of decisions that inflicts severe damage to the economy (temporary shutting down tourism and gaming, guaranteeing mask supplies, maintaining supply-chains, providing transparency of the situation), the resolution of the outbreak necessarily culminates in a fully guided, orderly resumption of work, active from $14^{\text {th }}$ February:

I. Entry to specific revenues requiring health statements (persons exhibiting a fever/cough are denied entry).

II. Sparsely distributing employees in work environments 
III. Strictly observing protective measures at work, including mandatory mask-wearing, frequent handwashing, cleaning, disinfecting of public areas, and ensuring good ventilation.

The orderly resumption of production enables Macau to balance nursing its wounded economy with effective outbreak control.

Alleviating pressures from socioeconomic recession: Post-outbreak, the Macau government immediately issued a series of temporary economic hardship measures [12], provided much-needed financial assistance to stimulate domestic demand and help small-medium enterprises overcome period of difficulties:

I. tax relief: 2019 income tax was reduced by 300,000 MOP (37,500 USD), an offer which was made to 2,970 companies, including small-medium enterprises. Another relief policy -with as many as 170,000 local beneficiaries - was the $70 \%$ refund of all occupational-tax paid in 2018, the maximum amount refunded being 20,000 MOP (2,500 USD). Hotels, bars, fitness centres, and 854 tourist service establishments were offered an exemption of the usual $5 \%$ tourism-tax for six months, and all vehicle license tax were refunded.

II. Implementation of "Small-Medium Enterprise (SMEs) Subsidy Program" to boost enterprise survival: this is a maximum loan amount of 2 million MOP (250,000 USD) for a maximum duration of 3 years with $4 \%$ interest. For SMEs that had been in operation for less than two years, addition interest-free loans are available, with up to 600,000 MOP $(75,000$ USD) offered in subsidy, and maximum repayment period of 8 years.

III. Livelihood support for the vulnerable: as compared to previous years, the 2020 medical subsidy plan saw an additional medical voucher (worth $600 \mathrm{MOP}$ ). A three-months subsidy was also offered for water and electricity usage and associated bills.

IV. Electronic consumer coupons for speedy economic recovery: to promote local consumption and boost domestic demand, the Macau government issued consumer coupons worth 3,000 MOP (375 USD) to each resident. It was once again announced, on April 8, that a further 5,000 MOP (625 USD) will be granted per person in the form of consumption vouchers, to be issued between August and December 2020 .

\section{Conclusion}

COVID-19 has taken a tremendous toll on Macau's economy. Exacerbated by an ultra-high population density, inadequate prevention and control measures in a city such as Macau has disastrous consequences. Macao has implemented efficient prevention and control measures, including proactive government action, early warning, strict boarder control policies, diligent implementation of community endemic control, and the government's Chief Executive prioritising public health over the economy. The resumption of production in Macao by mid-March has been formulated and strictly implemented by the government, with arranged measures for financial hardship during the post-epidemic period. Macau as a special administrative region holds the unique right to implement strict border control and community prevention measures. This is a substantially higher level of autonomy as compared with that granted to other provinces within mainland China. Therefore, the generalisation of COVID-19 control measures covered here may be limited, the operating model within Macau is isolated from that of other parts of China, and the SAR itself -- with all that is granted to its governance under the constitutional principle of "one country, two systems" -- is certainly not without its economic and political specificities.

\section{Authors' contributions}

XB drafted the manuscript. LY analysed the data and reviewed the manuscript critically. YB designed the project and did the critical review of manuscript.

\section{References}

1. Macau SAR Statistics and Census Service (EB/OL). 2020 https://www.dsec.gov.mo/getAttachment/f0477f64-33b6-473c-b4c08f9012b41431/C_DEM_FR_2019_Q4.aspx

2. World Health Organization. 2020. https://www.who.int/emergencies/ diseases/novel-coronavirus-2019/technical-guidance/naming-thecoronavirus-disease-(covid-2019)-and-the-virus-that-causes-it

3. Lin LT. COVID-19 confirmed case, death and recovery trend in Hong Kong. 2020. https://www.statista.com/statistics/1105425/hong-kongnovel-coronavirus-covid19-confirmed-death-recovered-trend /

4. Zhu N, Zhang D, Wang W, Li X, Yang B, et al. A Novel Coronavirus from Patients with Pneumonia in China 2019. N Engl J Med. 2020; PubMed: https://pubmed.ncbi.nlm.nih.gov/31978945/

5. News Macau Gov. 2020. https://www.gov.mo/zh-hans/news/277438/

6. News Macau Gov. 2020. https://www.gov.mo/zh-hant/news/326561/

7. Macau SAR Statistics and Census Service (EB/OL). 2020. https:// www.dsec.gov.mo/TimeSeriesDatabase.aspx

8. Lo IL, Lio CF. Evaluation of SARS-CoV-2 RNA shedding in clinical specimens and clinical characteristics of 10 patients with COVID-19 in Macau. Int J Biol Sci. 2020; 16: 1698-1707.

PubMed: https://www.ncbi.nlm.nih.gov/pubmed/32226287

9. Macao residents return home safely from Hubei. Macau Government Information Bureau (GCS). 2020. https://www.gov.mo/en/news/123406/

10. Xinhua News. http://www.xinhuanet.com/2020-03/16/c_1125718016.htm

11. China News. https://m.chinanews.com/wap/detail/zw/ga/2020/0316/9127298.shtml

12. 10-billion-pataca fund aiming to bolster support for employees and businesses. Macau Government Information Bureau (GCS). 2020. https://www.gov.mo/en/news/124630/ 